\title{
A Culturally Informed Personal Narrative of Indigenous Assimilation in Canada
}

\author{
Jonathan Pitt ${ }^{1}$ * \\ ${ }^{1}$ Indigenous Education, Nipissing University, 100 College Drive, North Bay, ON P1B 8L7, \\ Canada \\ *Corresponding author: Indigenous Education, Nipissing University, 100 College Drive, \\ North Bay, ON P1B 8L7, Canada. E-mail: jonathap@nipissingu.ca
}

Received: December 6, 2019 Accepted: December 31, 2019 Published: January 24, 2020

doi:10.5296/jsr.v11i1.15998ＵRL: https://doi.org/10.5296/jsr.v11i1.15998

\begin{abstract}
This article uses a narrative inquiry study to address the treatment of an Indigenous male through a historical and contemporary lens in the Canadian societal context. The purpose of this study was to unpack the assimilative practices through lived experience and apply an experiential reflective learning model process for the author. This narrative inquiry study concludes with a series of recommendations.
\end{abstract}

Keywords: Indigenous, Canadian, Western Eurocentric Worldview, mainstream media, racism, schooling 


\section{Introduction}

In this personal narrative I question the veracity of the historical and contemporary treatment of Indigenous peoples in Canada. Growing up in Canada and attending mainstream schooling I was taught a bedtime story of history that is so far from the truth yet always loyal to the colonialism inspired curriculum. As an Indigenous child growing up I was proselytized to the White-Eurocentric History of Canada. The chronicle that Canada was discovered by Europeans such as Cabot, Cartier, Champlain and so on was the fundamental mainstay of historical accounts for children. I was also inundated with stereotypes about 'Indians' as we were referred to then to the point that I often hated playing games the children played such as 'Cowboys and Indians' as we knew from the Hollywood movie stereotypes that if you were the Indian, that you would lose as the white cowboy always won. We were also flooded with racist jokes, Indians were always portrayed as drunks, lazy, and Indigenous women as sexual objects. I remember the first time I watched the cartoon Disney version of Peter Pan and the What Makes The Redman Red song showing stereotypes of Indigenous peoples as all living in tipis (teepees) wearing headdresses or feathers, whooping around and being barely able to communicate were staples from children's to adult television programming. The usage of terms such as 'squaw' and 'injun' used throughout the depiction like almost all representations until very recently were racist to the core. Similarly, when the thought came that these racist terms would not be still accepted in a dictionary I searched the terms 'squaw' and 'injun' today in 2019 using an online engine, I was given the answers: A North American Indian woman or wife and for the latter: A North American Indian. Shockingly a small indication said 'offensive' but no mention of racist or racism where there should have been. Although the Peter Pan movie was released in 1953, now some 66 years later the world in which we live in has not grown up and has stayed in Never Never Land. North America or Turtle Island has essentially remained a lost boy on Never Land Island and has not grown up since Peter Pan wore a headdress.

\subsection{Western Eurocentric Worldview}

Although much has been written regarding Indigenous peoples in Canada, most of the academic scholarly (Western Eurocentric approach to knowledge) has been done by very few Indigenous writers and too often non-Indigenous writers have been speaking for us. In my mind, this is wrong. As an Indigenous person I would not assume to know what or posses the appropriate mindset to write about what the experience of a Black, White, Hispanic, Jewish, Transgender, Russian or any other persons that I am not. The problem is, within Indigenous Studies, Indigenous Education and in the mainstream media we have people who are not of the traditional Indigenous territory or homeland; often not even Indigenous, telling Indigenous peoples about their own culture, heritage and this is a problem that is often overlooked and accepted as suitable.

I think institutions need to be held accountable for their systemic racism, I think people need to speak up when they hear racist comments or racially charged words in workplaces and those who commit racist acts or say racist things should be explicitly told they are racist and not mince words when confronting these issues. Photo ops with Indigenous peoples are an epidemic in institutions. Politicians also use Indigenous peoples in photos, while recently at a Pow Wow I observed a politician taking a 'selfie' photo among other photos of the dancers in regalia and the host drum, the politician also had to be told not to be taking photos during honour songs, grand entry and inside I felt sick seeing the all-too-common opportunist 
politician use Indigenous people for their own self-promotion.

I've seen Indigenous peoples be mistreated my entire life, I have seen Indigenous people working in Indigenous roles be essentially fired or let go so non-Indigenous people can have their job. I have attended job interviews for Indigenous jobs only to find one or sometimes no Indigenous people on the interview panel. As a male often my interviewers are all female with sometimes a token male on the panel. These imbalances of gender and race need to be addressed for reconciliation to be meaningful and not merely lip service. Institutions say they encourage visible minorities to apply for positions, however, often this is empty words and nothing more. These forms of systemic racism plague institutions, and in some cases force strong Indigenous female role models to resign and show little to no signs of improvement concerning undermining and exploiting Indigenous peoples (Pitt, 2007).

\subsubsection{Mainstream Media}

I recently read a newspaper article that made me queasy, literally and figuratively. The article was part of the right wing media ecosystem and this particular right wing tabloid serves as the echo chamber of sloganeering and white Eurocentric nationalism fuelling the populist political wave. It's racially charged articles like this that are anti-Missing and Murdered Indigenous Women's Inquiry (MMWI) of the single-mindedness brand that tell people that it's okay to downplay the mistreatment of Indigenous peoples. To claim that genocide was never the intent of Canadian policy, this type of tabloid journalism is dangerous and misguided. Often the writer's own bias and affiliations of journalists is on the far right. Perhaps some of these journalists would like to hold a town hall meeting with the families of those missing and murdered girl's and women's families and explain to them that what has happened isn't genocide. Clearly the country could've saved a great deal of money by hiring a moonlighting journalist from a tabloid to tell us otherwise rather than the governmental inquiry. I don't think journalists often read what they write about as the MMIWG report clearly outlined that the media has a role to play and unintelligible articles further prove the need for this inquiry and the calls to action.

Some Common Media (and Social Media) Racist Attacks on Indigenous Peoples Often Include:

- Decline in Natural Resources (e.g. Moose, blame the Natives, it must be because of what right-wing papers will term illegal over harvesting and out of season hunting).

- Decline in fisheries, or someone purposefully putting a 'ghost net' in a lake and calling the media. (Nets are expensive, fish feed families, find someone who can afford to throw away nets and you likely won't find an Indigenous person).

- $\quad$ Natives get free school

- Natives get free gas

- Natives get free money

- $\quad$ Natives are drunks

These tabloids that purport to preach conservative "family values" while also promoting scantily clad women in the same issue would appear to suffer from a moral identity crisis. The journalists who write for these propaganda machines don't see themselves as helping to 
maintain socio-economic and political structures that provide white people with a systemic collective advantage over marginalized groups such as Indigenous peoples. I'm sure in their minds they must think they are doing the right thing, of course how else do they look themselves in the mirror or sleep at night? Perhaps as the famous French-philosopher Michel Foucault says they have internalized the gaze of the white as better system and now function unknowingly as part of that power structure of banks, trade organizations, governments. Hopefully as a humanist it is not simply as sinister as overt racism and prejudice.

The need for further education and intelligent thought is overdue. When contemporary (2019) schooling curriculum documents refer to a vision quests as a "sensory experience" (FNMI Curriculum, 2019, p. 294) clearly shows that more remediation is needed to help our elected officials and people in decision making positions understand the issues they must have a working knowledge of. Off-reserve schooling authorities also have room to grow, suspending First Nations reps, not knowing how many First Nations they serve let alone which ones, or even what treaty area they reside in further provides evidence that work must be done to bring the contemporary leadership's understanding to a functional level.

Having the Ontario government publish the 2019 FNMI document without the original members involved is similar to having a buddy who thinks they know how to shingle a roof but really just has a vague idea. Chances are it's going to leak and in this case it has many too many holes to do the job properly. It is the equivalent of a Mathematics document that is close but not correct. For example, $3+3=5$, we wouldn't allow something inaccurate as this to be taught to children but in this case we have and it's wrong.

Canadians can talk about decolonizing the curriculum but what results is often good intentioned recolonizing of the learning by either a Western approach with Indigenized elements. Curriculum should be Indigenous centred and educators should be aware of not teaching Indigenous students with Western ways so they replicate it. Ontario's cancellation of the Indigenous curriculum rewrites will have a lasting impact to save a few bucks. A new curriculum done right would have been a step in the right direction for future generations of all learners.

Journalists in these right wing rags are hypocritical using 'at war' and 'for war' in article titles to attack labour unions in disputes with governments; yet attack the non-right wing government's official inquiry in MMIW using the term 'genocide' when it suits these same newspapers. The fact of the matter being that these non-Indigenous journalists are not experts in the topics (e.g. MMIW) that they write about; nor do they often source people outside of their supporters to present an unbiased article for their readers.

Canadian alt-right newspapers that were anti-gay in the 1970's and beyond now appear to have turned their hatred towards Indigenous women in 2019 and when looking back at how they "report" and I use that term loosely; anti-Indigenous it would seem is the new agitation approach they are taking to rally the simpleminded and sell newspapers. By promoting reactionary articles that reject ethical reporting in favour of disseminating deliberately controversial content these lookalike tabloids in the right-wing media echo chamber bypass unbiased reporting practices to sell newspapers to the gullible trusting people who are 
susceptible to believing things simply because they are written in a newspaper.

Hiding behind "community guidelines" many right-leaning media sources allow articles by unspecified authors and anonymous commenting on their stories, despite sending notifications to these would-be mainstream right wing media ecosystem sources, comments such as the following racist post clearly blaming Indigenous people for potential reductions in fisheries natural resources were commonplace even on an article published on Indigenous Peoples' Day, June 21, 2019: “...That's great news! Sorta offsets the 200 million in lost tourism revenue with the collapse of the lake...sports fishery." It is important to note that the Treaty Rights of Indigenous Peoples in the territory have been blamed for lower numbers of fish, moose, and other resources while in nearby areas numbers are healthy. At no point do the 'coffee shop commandos' blame governmental mismanagement, harvesting for sport, and so on. It is simple and easy to blame Indigenous peoples for all that ails you including economics, not unlike Germany did in the 1930's with Jewish people.

\section{Moral Vacancy}

There exists an overt moral vacancy within Canada towards Indigenous peoples. Canada is a racist country. Let's not pretend it isn't or that is too extreme of a statement. Eurocentric Canadian Society hasn't changed since first contact with Europeans Explorers and Fur Traders. I know that's a relatively strong proclamation, however, it is the truth when the 'top percenters' in Canada continue to find new and creative ways to keep marginalized peoples such as the Indigenous First Peoples from being treated with respect; notice I said respect not equal as when the term equal gets tossed around non-Indigenous people often want to dust off Jean Chrétien's White Paper from 1969 and assimilate Indigenous peoples faster than a politician shredding documents before an external inquiry. Canada is our home on Native land. The latter part may also upset some readers, nevertheless, it is also truth.

Our Indigenous uniqueness and differences between groups (e.g. FNMI), and I'd argue from First Nation to First Nation has been a significant factor in why assimilation hasn't succeeded and should be celebrated. The flip side of the coin is that these differences also present a major challenge to political movements and unity.

\subsection{Indigenous Historical-Contemporary Blaming}

Indigenous fighting with settlers has always been represented through a white Eurocentric lens. For example, In the United States these conflicts are often referred to as the 'Indian Wars' and in Canada examples such as the 'Riel Rebellions' or the ' 1885 and Northwest Rebellions' all suggest that Indigenous peoples were at fault or the aggressors much in the same way Hollywood movie stereotypes portrayed Native peoples for over half a century. These labels and stereotypes have lead to an indoctrination of white as better and Indigenous as the lower-level problem. The reality is without Indigenous assistance the first settlers, the fur trade and conflicts such as the War of 1812 could have and likely would have gone terribly wrong for the settlers in what is now Canada. Without Indigenous help from well-known warriors such as Tecumseh, Canada could very well be American soil today. 
What is often overlooked is that each and every commonly known Indigenous warrior, Pontiac, Tecumseh, Louis Riel, Big Bear, Poundmaker and others were persecuted and yet, it is their efforts that solidified rights for the Indigenous peoples of Turtle Island that would probably not have occurred otherwise.

During the First and Second World Wars both my grandfather and great grandfathers served in the Canadian Forces. I also had the honour and privilege of getting to know my father's close friend and mentor who was a rear gunner on one of the Lancaster Bombers during WWII. Throughout both of these catastrophic wars so many Indigenous veterans from Canada and the United States fought for countries that hadn't fought for them and if anything, Canada had been wiping out the "Indian" through practices and policies. Nevertheless, it is almost seventy-five years since WWII ended that discussion of the vital roles played by Indigenous war vets are finally becoming mainstream, for example, media attention to Indigenous language speakers who bravely served as the code talkers against the Nazis and their allies. I often wonder why it has taken such a ridiculously long time for Indigenous peoples to be given their recognition for helping such anti-Indigenous nations and it reminded me of a more contemporary example. When I was a young man a classmate of mine had a parent who fought in the Gulf War and back in those days, before the Internet and Social Media, we relied on encyclopedia sets for facts and our major newspapers, television and radio through war correspondents to report the situation on the ground. The problem is, the way things happen and the way they are later told to us are often related but not reliable. This controlling of the narrative has been happening with the portrayal of Indigenous soldiers and not acknowledging their efforts in times of war for hundreds of years. In more contemporary times, I recall a soldier who fought in Iraq the second time telling people that what was happening during the fighting and then what he was watching back in the encampment on television were worlds apart in their validity. The history books, have for too long not given the Indigenous soldier the recognition they are owed.

This mandate to control the narrative has been present since First Contact with Europeans and I strongly believe it is just as strong and perhaps in some ways even stronger in contemporary society. If anything, because these thought patterns have been around for such a long time and have been mainstream in Canadian society, most people do not question them, no more than they might question a landscape on a major highway that they cannot see past the first few hundred meters to the clear cutting beyond their line of sight. Today, the dominant group holding power who wishes to control and suppress information must work hard as a result of Social Media and the Internet to create that echo chamber of indoctrination vital to maintaining the status quo. Keeping Indigenous people down has been a staple in the very fabric of Canadian daily life and to deny such realities only further perpetuates these essential areas for decolonization improvement. For instance, in many communities they award Canadian athletes for their achievements through sport, however, if you visit the web sites of many of these recognition bodies and view their archives you will see very few (if any) Indigenous athletes recognized and not because there have not been Indigenous athletes throughout the twentieth and twenty-first centuries. Historically their have been Indigenous hockey players in the NHL who have self-identified as Indigenous, but many often have not 
and some have only self-identified in recent times. Policy changes must be made throughout Canadian sporting organizations and recognition bodies to decolonize their practices for Indigenous peoples.

\subsubsection{Subtle Racism Yesterday and Today}

Another Indigenous Peoples' Day in 2019 has come and gone, this day always leaves me deep in reflection as to the current state of affairs across Canada. The sense I have is not one of joy and optimism for the future of this country, in fact, I would say "I'm a worried man" (to use the 1998 song lyrics of Johnny Cash). From nearly the entirety of the country we hear crickets, if you want to weigh the success of reconciliation and decolonization even on a purely token level, ask yourself did your employer even bother to send out an email acknowledging the day? If your workplace resides in a traditional territory did they recognize it? Any mention of the contributions made by Indigenous peoples at all? If the answer is no, then the chains on the football field of understanding and bringing people together haven't moved an inch and scoring any points towards disengaging the established settlement occupation are a 'Hail Mary Pass' so to speak (pun intended) and we're not going to even reach a first down in reconciliation without some heavy moving done by the non-existent offence we have yet to create. We have no playbook, no coach, no offensive coordinator. We have a few special teams but without a solid team game this "reconciliation bowl" will not succeed as well as it clearly could.

Sports analogies and Indigenous culture are complimentary. Indigenous athletes have been and continue to be a force within the sporting world. My father, a man proud of his Indigenous heritage was a Canadian track and field national title winner in 1965 in the 880 . One of the questions I think Canadian culture has to ask itself in general is how many Indigenous athletes are recognized for their achievements? I know from my own curiosity when I look at the hall of fame for major sports, there are championship winners, MVP winners not in these fraternity-like bodies when they clearly should be based on their accomplishments. Why would they not be? I think if you look inside your heart and mind and ask yourself you'll easily find the answer. All major sports and most communities of a certain size across Canada have these halls of recognition. When you look at the membership within them, how many are Indigenous? Let alone do they even have a designated Indigenous representative on the selection board? When Indigenous athletes are not recognized, not celebrated for their achievements in Canada it does two things. First, it does nothing towards reconciliation and acknowledging athletes who without a doubt deserve recognition. Second, it diminishes the hall of fame for it is not a true representation of athleticism when it does not account adequately for all peoples.

The reality is not what modern movements have told us, like it or not men and women need each other. In the past, the genders relied on each other for survival, we hear many people today mentioning the role of women as 'life givers' and the sacred feminine of givers of life. This is a traditional role in the purest sense and traditional roles, if they are the heart of returning life to balance for Indigenous peoples means just that, traditional roles for men as well. I know as a male I am happiest in the role of provider and protector, that is not to say that I do not enjoy spending time with my children or taking part in their upbringing, rather that I am most fulfilled when listening to my biology my DNA and trusting it. The social 
constructs that exist today cannot undo billions of years of biology at work in our world. Crustaceans for example and serotonin have been at play for billions of years, a social construct cannot erase that reality within a generation or two (Peterson, 2018).

The central dilemma or observable problem existing in contemporary society is in stark contrast to what Indigenous Elders and leadership have been advocating for in a return to traditional values or to decolonize from the settler Eurocentric approaches. Contemporary Eurocentric society calls for greater and greater assimilation across societal boundaries. These movements or push forces if continued will ultimately attempt and likely succeed in changing the way in which Indigenous cultures function. For example, traditional Anishinabe drums had four posts on them and have now been largely removed on many to incorporate a more competitive Pow Wow approach at many cultural gatherings, as well as the drum not being located in the center of the circle but at various locations within a canopy similar to a competitive Pow Wow, these modernizations do not fully account for the spirit of the drum and the role it plays in culture. Likewise, we see females joining or standing near the male drum circles, in some instances even joining the men. This occurrence is not in harmony with what the cultural teaching are but transpire due to the larger societal happenings pushing for a teardown of gender specifics in the modern world.

Make no mistake, the modern forces at play are assimilative by spirit and will be equally as harmful as residential schools, the Indian Act, racism and the systemic discrimination that has befallen Indigenous culture and continues to this day. The difference is it will take root from within Indigenous culture unknowingly and as time passes the old ways will be forgotten like so much of our traditional knowledge that has been lost to time. Ojibway writers such as Basil Johnston, have said that traditional practices such as vision questing helped Indigenous people find their path in life or purpose and although women could vision quest their path as life givers and mothers was vital and already recognized. (Johnson, 1987). This notion would in today's society be considered backwards or perhaps archaic by Eurocentric North American Society, not surprisingly this is the same epidemic of worldview that came into play with First Nations when Europeans arrived in Turtle Island, that Indigenous Peoples were savages and backwards. The assimilation wheel therefore continues through a "modernization" effort that perhaps well-intentioned is not different than introducing foreign disease, debt, and suffering that would not have existed otherwise. Sadly, despite the MMIW inquiry by the Canadian government, Saskatchewan continues using 'birth alerts' to track Indigenous babies in June of 2019. (Taylor, 2019).

Recently, while walking in a high Indigenous demographic area I read a sign that was intended jokingly although I did not share in the humour. The sign said "They need a dating app for 40 year old divorced women, looking for a trio of other 40 year old divorced women who want to just golden girl the (expletive) out of the rest of their lives." I found this rather sad to be honest, I grew up watching the television show referenced and one of the central formulaic themes was failed relationships and a failure to find happiness. Celebrating a lack of traditional union in our life cycles is not the pathway forward for Indigenous peoples, our Indigenous traditional marriage ceremonies are sacred. We cannot treat our lives like a buffet dinner and pick and choose what parts of traditional culture we like and disregard those we 
may not like or find challenging. This getting the pay check without putting in the work however, is a modern entitlement concept ever present in today's world. Modern technology has made our lives easier and less arduous in the past one hundred years. Since the Great War (WWI) the need for traditionalism has declined and we have replaced the need for men and women to work together to survive.

Sadly, even politicians are not speaking truth as well-known Conservative Senator Lynn Beyak published overtly racist letters on her web site that included comments such as:

- Trade your status card for a Canadian Citizen...All Canadians are then free to preserve their cultures in their own communities, on their own time, with their own dime.

- I don't take a stand against the chronic whining and unreasonable levels of expectations that are exhibited by some Indigenous groups that seem to keep inventing new ways to achieve a cash grab.

- Certainly, the decision to assimilate first nations into Canada was and remains to be the correct one...I deeply resent having to pay taxes that are in part used to subsidise first nations programs...

- The endless funding pit of reserves has to stop. These people need to join the commerce world and work for money.

(Source: JAGO, R. Why Is Senator Lynn Beyak Publishing Racist Letters on Her Web Site. The Walrus. January 3, 2018.)

\section{Conclusion}

In my community, there always seems to be a non-Indigenous police cruiser on the Trans-Canada Highway near the reserve lands but seeing a police car away from this area has been rare. I've been followed around stores in town, pulled over and questioned as part of "routine" traffic stops, but there always seems to be an excuse for these actions or someway to justify these behaviours. Its profiling plain and simple, if I wear my hat backwards or I am driving my car with the high horsepower engine instead of my old truck I'm more likely to be pulled over. I've never once been stopped in my old pickup truck.

I fear the police more than I fear a biker gang, that's a sad reality of the world in which we live. I was always taught to respect law enforcement officers but I also know the potential of some and just because they wear a uniform doesn't make them trustworthy, if anything it does the opposite for me as an Indigenous male. I've been pulled over countless times without cause and delayed, I have been followed and harassed to my workplace during my lunch break and pulled over with my child in car seat simply because I was going the speed limit. I've been forced to give a breath sample when only drinking soda pop the entire evening, I have had non-Indigenous police come onto the reserve and been questioned about stolen property without any cause and that list goes on.

I will always remember sacrifices made by war veterans and in times of peace, both 
Indigenous and non-Indigenous. Like my grandfathers they experienced things no human being should ever lay eyes on. I wonder how they would feel given the way our society behaves in this day and age. Would they think their ultimate sacrifice was worth it given how we treat each other now? Canadian history in this regard like its relationship with Indigenous peoples is equally dark and disturbing. Canada turned away Jewish refugees, interned minorities during war time including famous Canadians like Dr. David Suzuki interment camps across Canada.

Genocide doesn't only take place in concentration camps under the leaders of the Hitlers and Stalins or mass extermination graves in places like Rawanda. Genocide in a Canadian context is like other catastrophes in Canada's history, more cloaked and camouflaged. It's the mindset that becomes part of what is acceptable and what is not in Canada and the true nature of things shows itself when our leaders say things like "Get the fucking Indians out of the park" (CBC, 2006) and then unarmed protestors are shot by the "sovereign citizens" that are suppose to be defending democracy rather than devaluing human life. The question shouldn't be whether it was genocide or not, white culture instead of just accepting their own government's MMIWG report would rather argue about genocide than look to ways to implement the findings of the inquiry. This push back to the MMIWG report itself further highlights the racism epidemic towards Indigenous people within Canada and sets reconciliation back decades.

\section{Recommendations}

Indigenous women have told me they want the males in Indigenous communities to stand with them but that may not be easily done for two reasons. First, Indigenous men have been dealing with intergenerational trauma which is something their white male counterparts have not. This fact, Indigenous women must accept and work towards helping males if they want them to stand with them in a more holistic way. Second, males regardless of race have been in the decline as a result of external pressures. The need to return to traditional teachings and traditional roles is lost in contemporary society, when it is so badly needed most. This simultaneous undoing has paralleled the attack on Indigenous people at the same time, although beginning much later beginning around the end of World War II in North America.

There is talk of grassroots solutions, community based, but those things will only be done as checklists by white governments and one-off un-sustained pieces. Self-government and political movements that have gone silent such as the League of North American Indians, National Indian Government need to be brought back in full force as the only real and lasting change comes from taking a stand while maintaining structures such as the assembly of First Nations. Unity has always been and will continue to be a major hurdle as white governments divide and conquer.

Treatment of Indigenous peoples by law enforcement, healthcare workers who treat people seeking pain medications as addicts and so on needs to change. An Elder once told me there are only two groups of people in Canada, the Indigenous First peoples and settlers. Settlers 
who signed legally binding contracts in the form of treaties that do not extinguish inherent Indigenous rights. Reporting racism and Education should be mandatory for all Canadians and all politicians should accountable regularly as to what they are doing to support Indigenous issues and held responsible for this duty. If we are going to move forward it must come from Economic Development and Education. Without an economic base we cannot forge the future the way it needs to be. This should be the focus for the next century.

\section{Acknowledgement}

The narrative research could not have been accomplished without the support of my ancestors, Elders, family and community members who encouraged and continue to encourage me to speak truth. Miigwech.

\section{References}

Cash, J. (1998). I'm a Worried Man. Retrieved 4 December, 2019 from https://www.youtube.com/watch?v=EGxhk2NkeEI

CBC News. (2006). Harris lied over and over again, lawyer tells Ipperwash Inquiry. Retrieved $4 \quad$ December, 2019 from https://www.cbc.ca/news/canada/toronto/harris-lied-over-and-over-again-lawyer-tells-ip perwash-inquiry-1.627280

Chrétien, J. (1969). The White Paper. Retrieved 4 December, 2019 from https://www.aadnc-aandc.gc.ca/eng/1100100010189/1100100010191

FNMI Studies, The Ontario Curriculum, Grades 9 to 12. (2019). Retrieved 4 December, 2019 from

http://www.edu.gov.on.ca/eng/curriculum/secondary/First-nations-metis-inuit-studies-gr ades-9-12.pdf

Jago, R. (2018) Why Is Senator Lynn Beyak Publishing Racist Letters on Her Web Site. The Walrus. $\quad$ Retrieved 4 December, 2019 https://thewalrus.ca/why-is-senator-lynn-beyak-publishing-racist-letters-on-her-website/

Johnson, B. (1987). Ojibway Ceremonies. Canada: McClelland \& Stewart.

Peterson, J. (2018). 12 Rules for Life an Antidote to Chaos. USA: Random House Canada.

Pitt, J. (2007). White History Month? In Many Voices, Many Journeys, an Anthology of Stories by Aboriginal Teachers. Canada: Canadian Teachers' Federation Press.

Report reveals Indigenous community creates a huge economic impact. Baytoday.ca. (2019). $\begin{array}{llll}\text { Retrieved } & 4 & \text { December, } & 2019\end{array}$ https://www.baytoday.ca/local-news/report-reveals-indigenous-community-creates-a-hu ge-economic-impact-1517535

Taylor, S. (2019). Saskatchewan to continue using 'birth alerts' to track Indigenous babies 
despite MMIW inquiry's call to stop. Globe and Mail.

\section{Copyright Disclaimer}

Copyright for this article is retained by the author(s), with first publication rights granted to the journal.

This is an open-access article distributed under the terms and conditions of the Creative Commons Attribution license (http://creativecommons.org/licenses/by/3.0/). 